University of New Orleans

ScholarWorks@UNO

\title{
Dimensions of resiliency: essential resiliency, exceptional recovery and scale.
}

Shirley Laska

University of New Orleans, slaska@uno.edu

\section{Recommended Citation}

Laska, S. (2012). "Dimensions of resiliency: essential resiliency, exceptional recovery and scale." International Journal of Critical Infrastructures, 8 (1), 47-62.

This Article is brought to you for free and open access by the Center for Hazards Assessment, Response and Technology (CHART) at ScholarWorks@UNO. It has been accepted for inclusion in CHART Publications by an authorized administrator of ScholarWorks@UNO. For more information, please contact scholarworks@uno.edu. 


\title{
Dimensions of resiliency: essential resiliency, exceptional recovery and scale
}

\author{
Shirley Laska \\ Center for Hazards Assessment, \\ Response and Technology, \\ University of New Orleans, \\ New Orleans, LA, 70148, USA \\ E-mail: SLaska@uno.edu
}

\begin{abstract}
Not only is resiliency a term with a myriad of definitions microscopically specified by a wide variety of social and bio/physical scientists and practitioners, it is also incredibly complicated even when treated by individual academic/government/non-profit and business practitioners who are convinced that they have the perfect definition. By then linking the concepts of infrastructure and community to resiliency, not only does additional complexity emerge but also a powerful imperative to examine the basics necessary to achieve resiliency within these interrelated concepts. The lens of the applied academic observer situated at 'ground zero' for not only one but two major catastrophes within a micro minute span of less than five years (Hurricane Katrina and its 2005-2007 relatives and the British Petroleum oil well blow out of 2010, layered on pervasive localised sea level rise due to delta subsidence) is the 'data' analysed to support the arguments of this paper about what must be considered with regard to infrastructure and community to even hope to achieve a resilience state: essential resilience, exceptional recovery and serious appreciation for the need for a greater recovery scale.
\end{abstract}

Keywords: Katrina; essential vulnerability; multiple hazards; infrastructure and social linkages; exceptional recovery; scale.

Reference to this paper should be made as follows: Laska, S. (2012) 'Dimensions of resiliency: essential resiliency, exceptional recovery and scale', Int. J. Critical Infrastructures, Vol. 8, No. 1, pp.47-62.

Biographical notes: Shirley Laska is a Professor Emerita of Sociology and past Founding Director of the Center for Hazards, Assessment, Response and Technology (CHART). She is the past President of the Southern Sociological Society. In 2000, she received the American Sociological Association Achievement Award for her work in Environment and Technology Research. She received her PhD in Sociology from Tulane University.

\section{Introduction}

At the beginning of this first decade of the 21 st century, social scientists were excited about a concept to which they were being introduced from the bio and physical sciences. We social scientists are taught to resist such crossover offerings. Other than the genetic determinism that promotes particular behaviours, we believe that physical 'laws' do not 
explain how we behave. Humans give meaning to the physical before they respond; the physical must become a symbol, i.e., have that meaning, before action about it takes place. Such a layer of meaning is thought not to be part of the ecosystem's action process. Ecosystem resiliency has no 'mind force'.

But, despite the admonitions to do otherwise, the ecosystem term 'resiliency' was embraced to explain human behaviour because its meaning was useful to imagine conditions, outcomes, different from the meaning given by terms we had been using in community and risk response analysis. ${ }^{1}$ It overcame the objections of 'development' which implies that a community is ill fated unless it is growing; similarly 'sustainability', while it is quite a good concept, has an intransigent, rigid imagery of steady state. Resiliency encourages us to think about variable conditions, responses and how they contribute fluidly to a community's capacity to continue functioning while in effect re-inventing itself. It also has a quality of encouraging imagining, reflection, that the other terms may not (Tatsuki and Comafay, 2010). Consider the difference in capacity to imagine positive futures between 'vulnerability' and 'resiliency'. Given the amazing challenges that communities worldwide are increasingly facing with regard to environmental hazards, we must put the term resiliency to the challenge for this quality and for others that it has. We need every symbol we can conceptualise, and every theory that uses it, to guide understanding and action toward the changes in community form and process that must be recognised and achieved.

\section{The setting}

New Orleans, Louisiana is a metropolitan area which sits in a bend of the Mississippi River, 90 nautical miles from the Gulf of Mexico. The river delta at that proximity to the sea is flat, sinking and subject to rapid loss of the existing land due to: the leveeing of the river and thus the lands inaccessibility to its spring sediment load; the naturally caused diminishment of the land by subsidence from organic decay of the sediments and from powerful storm impacts; and the human economic uses, especially navigation and oil/gas exploration and production. This locale presents tremendous risk to property and to life when the tropical systems cross the delta flooding the area and the levees compound the risk by preventing the water's return to the sea. No exits from the city on the east bank of the river are available that do not traverse land below sea level and water bodies. Unfortunately, it might be possible to state with no challenges, that the city is the most vulnerable to flooding of all US coastal cities. What it experienced with hurricane Katrina would be the data to support this unfortunate claim and the social vulnerability present would make the 'capping' argument. Added to these physical qualities is the way in which the city was created by development interests that enhanced the risk due to the manner in which it grew into the riskiest, i.e., low lying, parts of the ecosystem, in effect 'manufacturing' more risk than the environment itself might have posed (Youngman, 2011).

\subsection{Resilience as 'bedrock'}

The residents of New Orleans who had no automobiles or who chose not to use them to evacuate the city when Katrina struck - some because they did not have the money to travel - languished in the Super Dome and then the Convention Center, awaiting a rescue 
with the expectation that it would occur at a pace and quality at least equal to what the US military has provided for other countries experiencing catastrophes. That was not to happen. They remained with only limited water and food for six long, sweltering days and in full view of the world through the media. The world asked: 'Why?' And while we applied social scientists living and working at 'ground zero' began to sense the answer, we were reluctant to articulate it. The reality was that the storm and the flooding that followed a day later 'revealed' a community with massive vulnerabilities not just, or even most importantly, to the physical ones described above, but rather to the social - structural inequities, poverty, racism/race divisions and a government barely operable.

A catastrophe occurred rather than a disaster because the community had no capacity to respond. It also occurred, however, because the community had no comprehensive appreciation of the risk we were under, nor had it taken risk reduction seriously. How horrific it was to watch the suffering of those left behind. Their sacrifice indelibly marked into the mind of Americans what such vulnerability brings. It was the most dramatic transformation of thinking by a national population of a sociological concept than ever could have been imagined. Social and economic vulnerability was the cause of the catastrophe, not the wind, rain, storm surge or even the faulty hurricane protection. And the country knew it.

It became very evident from these observations that resiliency requires consideration of 'essential' bed rock resiliency, rather than merely post-event capacity to rebound as has been extolled through the application of the term too directly from the physical concept of resiliency (Laska, 2008). While an ecosystem does not think or prepare, humans can/do. And most important to essential resiliency, they can strive for it on a normalised, daily basis, not simply in the framing of the immediate response to the hazard event.

\section{2 'A mere glancing blow'}

This approach to resiliency is not the usual one. Others at this conference will have expanded the more widely accepted definition that focuses on what will happen to a community when it experiences the hazard event, be it a swift one or a long term. Resiliency, according to the more accepted definition prevents the community's capacity from declining too far in the recovery phase thus enhancing the prospects of a rapid return to the conditions before the event. The difference is that the emphasis of the more common definition is on the preparation for and response to the disaster. If one approaches resiliency in the manner proposed herein, one would expect that the dip would be tiny and the recovery slope very steep, a goal also of the more traditional definition. But in the approach I am proposing, the impact of the physical event would be merely 'a glancing blow' because of the 'essential' resiliency that characterises the community. By this I mean a complex form of resiliency that is pervasive.

An example demonstrates the difference. A very large emergency response for those without cars or the infirmed for example would not be necessary as it is today in New Orleans if essential resiliency existed. Families and individuals as well as neighbourhoods would be well educated and concomitantly would contain well employed workers. Thus, they would have cars to evacuate and money to pay for gas, motels, and food. Medical services would be available and affordable so that prevention would be emphasised and medical issues treated early. Thus, the populous would not have the high 
level of illness manifested in New Orleans that requires special considerations in the evacuation plan. And adult children would not have to leave the city for employment and thus leave their older parents to fend for themselves with family support networks weakened.

Consider the answer to these two questions:

Q1 How many shelter beds are needed to evacuate a socially/economically vulnerable metropolitan region? A1. 109,000 ${ }^{2}$ (Donley, 2007)

Q2 How many shelter beds are needed to evacuate a socially/economically robustly resilient metropolitan region? A2. 0

Both answers are underestimated: More beds are needed than are currently provided for this socially/economically vulnerable region and more than zero beds would be needed for even the most essentially resilient region. But the gap between the shelter needs of the two different types of communities is not underestimated. It is a chasm. Right now New Orleans has only the resiliency possible with such essential vulnerability.

To explore this idea further, it is possible to take this logic and work backwards from what would be needed for a resilient community to exist. The logic is similar to the analysis which says that the roots of crime lie with inadequate public education not with the number of prisons built to receive the criminals. Resilient 'shortcuts' such as the efforts since Katrina reveal the 'essential' vulnerability. A politically (Freudenburg et al., 2008), economically, socially (Laska and Morrow, 2006) and educationally 'healthy' community is a resilient community - to whatever risk comes along, economic, natural hazard, health or technological.

Or as with the Louisiana example, the region would have been, would be, more resilient to the onslaught of the co-occurrence of the multiple hazards - economic, natural and technological disasters that have occurred if it had practised essential resiliency. We have and are currently experiencing:

- major delta land loss exacerbated by oil exploration that mimics eustatic global sea level rise

- the natural hazard events of multiple, powerful hurricanes - Katrina and the other three hurricanes of the 2005 and 2007 seasons (Rita, Gustav and Ike)

- two technological hazards, the flood wall failures and the oil rig blowout

- the international recession

- the beginning effects of sea level rise.

It would easy to argue that the region is an anomaly of what may be the situation of other world regions but disaster events since, including the Japanese triple event of the earthquake/tsunami/nuclear power plant accident and the challenges of response and recovery of a developed society tell us a different message.

In the case of southeast Louisiana and Japan, the burden of a resilient response has been challenged perhaps beyond what an essentially resilient community can handle; but with such social and economic vulnerabilities as exist in southeast Louisiana, the challenges have been overwhelming. 
In an essentially resilient region not only will the risk 'driver' have less of an effect, in some cases the actual risk might have been prevented from occurring. In fact some of the events just iterated are even less likely to have happened in the first place if Louisiana had been more robust in its essential resilience. 'Essential' resiliency would have reduced the list of risks just described above.

For example, we ask ourselves if we should have/could have done more to demand better treatment of the ecosystem by the oil/gas industry. Why did not we? Perhaps because as a peripheral, extracting region we traded environmental safety for economic benefit and thus the risks have been 'stacking' (Freudenburg, 1992). And following this logic, the argument would continue that moving fast forward to those resilient elements to be implemented just before the disaster event misses the point of where the prime target of resiliency effort should be: very early in the social/economic bedrock.

Can this hypothesis be tested, that is of observing the differences for two communities that experience a similar hazard of a similar magnitude or of comparable hazards but are different in their basic resilience dimensions? It is likely possible to do so. And one could continue the analysis by considering the differential need for emergency and immediate recovery resources between the two communities. Providing the latter is very costly and drains state and local resources. One of the reasons that the state of Louisiana is attempting to expand its shelters to retain its evacuating citizens within its borders is because it is required to cost share the expense of sheltering its citizens that the Federal Emergency Management Agency (FEMA) pays for outside of Louisiana. ${ }^{3}$

\section{3 'Exceptional' recovery}

Following this logic of 'essential' resiliency, there is a requirement for 'exceptional' recovery with each disaster event so that the basic resiliency capacity can be built up in the recovery from each disaster event that occurs in the same location. The diagram below demonstrates this process. By incorporating vulnerability reduction efforts systematically and calculatingly when rebuilding from a severe damaging disaster, the essential social institutional and social resiliency capitol is accumulated through the enhanced structural improvements. FEMA administrator, Craig Fugate, in speaking at the University of Colorado Natural Hazards Workshop in 2008, before assuming leadership of FEMA, stated (paraphrased): A community that does not rebuild back safer is not a recovered community. This is to the point that the diagram represents (Figure 1).

Growing in appreciation of the linkage between the physical and the social, challenges the traditional ways we usually think. The US Army Corps of Engineers gave a UNO-CHART team of social scientists and practitioners (the latter mostly former state and FEMA senior recovery and mitigation officials now with disaster consulting firms) an opportunity to consider these issues (Laska et al., 2009). The Corps' principal activity is building structures - dams and levees - that have as their goal protection of communities and human activities. However, very little imagining of the linkage between the structural and social is undertaken by the Corps before the structures are built. Construction decisions have been based heavily on engineering issues once 'the project' has been blessed by political (Congressional delegation) leaders who must advocate for the funding to be appropriated and authorised. 
Figure 1 Resilience deltas when community function is/is not enhanced by pre-event vulnerability reduction measures

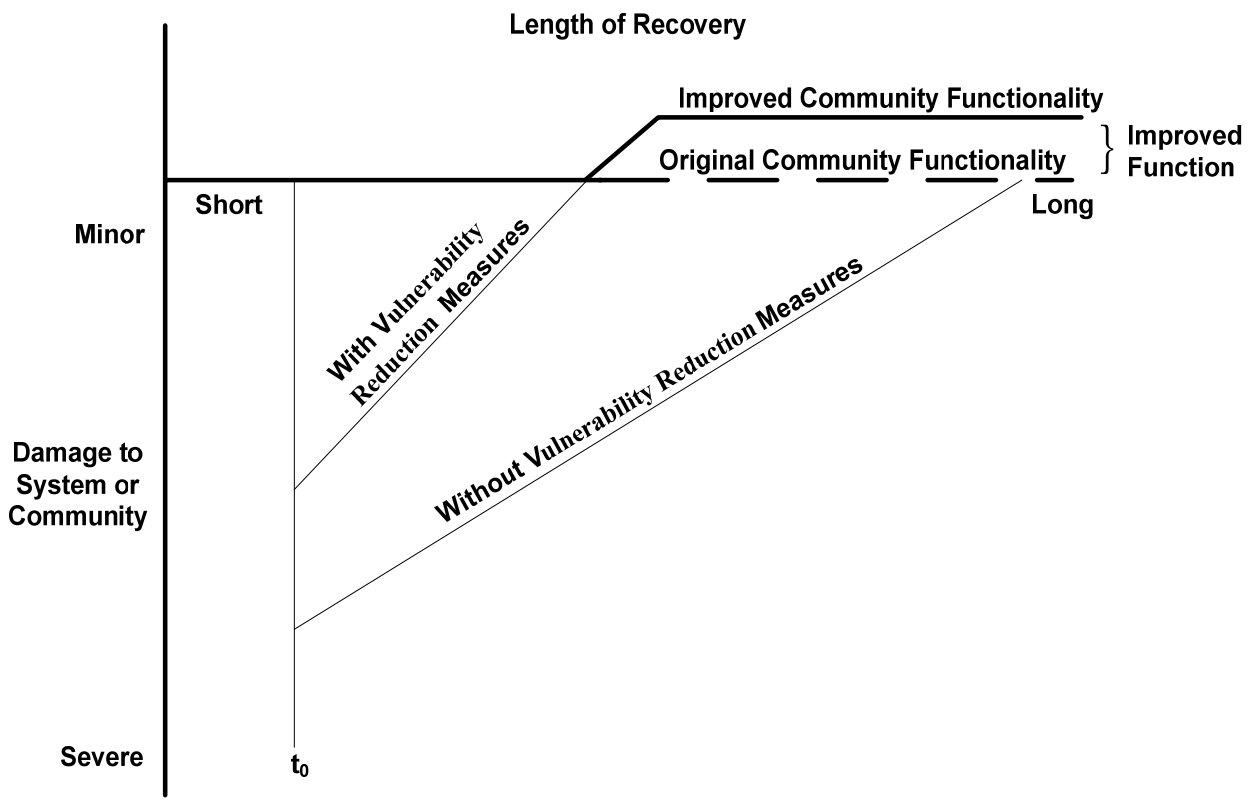

Katrina was a 'wake up call' to suggest that more must be done with the physical/social relationship. The Corps calls these community elements 'other social effects' (OSE) and they are distinguished from the national and regional economic benefits of a project and the environmental impacts that might cause harm. The economic and environmental are the three of the four that are required by law to be considered; the fourth, the social benefits are not required to be considered and thus have been ignored since they were first described in the 1970s (Dunning and Durden, 2007). The team (Laska et al., 2009) conceptualised the social structures (Table 1) and processes (Table 2) that must exist in a resilient community. ${ }^{4}$

To best use the government resources that will be applied to addressing a flooding problem, the report argues that through a community engagement process such as social impact assessment (SIA) community residents must be asked what of these social structures do they particularly value and thus want protected. Together the communities and the government agencies should together determine how best they can be protected with the possible assistance of a physical structure of a particular configuration. In other words it should not be assumed that the physical will help - some specialists believe macro infrastructure enhances risk - or that a particular engineering proposal is the best design. ${ }^{5}$ With the focus of this workshop on social capitol, resiliency and community engagement, the time could not be better to bring the OSE back fully into the conversation for not only the Corps' projects but also for all other physical infrastructure efforts - hazard-hardened buildings as well as levees - initiated by all federal and lower government level agencies. 
Table 1 Community and institutional structures and resources

Education

- Educational opportunities

- Educational physical infrastructure and personnel

- Traditional knowledge, especially ecological

Criminal justice

- Community crime/violence safety

- Police, court, incarceration, domestic violence shelter facilities and personnel

- Informal 'policing' by community members

Neighbourhood/housing

- Housing characteristics: supply, cost, condition, tenancy (rent vs. own)

- Residential stability

- Community sub-area infrastructure, public service and neighborhood businesses

- Homeless programs

- Historic buildings and districts

Household/family

- Density/home sharing

- Support services for homeownership

- Safe housing for all income levels

Business

- Commercial/business stability/diversity

- Small business sector

- Informal exchange (bartering) networks

- Family livelihood systems

Income, employment, labour force

- Economic activity of population

- Livelihood activities of community

- Personal/household income

- Personal household livelihood

- Employment/income dispersion/stability

- Occupational diversity

- Community socioeconomic characteristics
Health and physical safety

- Healthy lifestyle

- Access to clinical care services (especially: trauma, gastrointestinal, neurological, diarrheal outbreak investigation, poison control referrals, national pharmaceutical stockpile, etc.)

- Access to disaster mental health (especially: psychological first aid, mental-health referral)

- Access to environmental health services (especially: septic and water inspections, food service inspections, surveillance for vector-borne diseases)

- Access to specialised high-technology lifesaving equipment and therapy (e.g., dialysis, ventilators, ACLS, ATLS, etc.)

- Informal care-giving systems

- Access to specialised services for vulnerable populations unable to physically or psychologically access necessary care

- Community health risk factors environmental, mental health exposure, vulnerable populations

Mortality rates, causes

- $\quad$ Surge facilities and personnel (e.g., emergency-worker liability, ESAR-VHP volunteer call-up systems)

Governmental organisation

- Organisational structure and functioning of government

- Sustained critical infrastructure (especially: telecommunications, water, sewage, power, streets, public buildings, etc.)

- Provision of public services (e.g., planning, taxation, permitting, public transportation, education, public health, emergency ops/incident command, etc.)

- Exercise of democratic participation (e.g., voting, letters to the editor, civil action groups, billboards and posters, etc.) 
Table 1 Community and institutional structures and resources (continued)

Community social services

- Availability and access to basic range of formal social service programs (e.g., family counselling, parenting, family violence, seniors, chemical dependency, children services including child care, disabilities, welfare benefits/job training, foster care, mental health, disabled transportation, etc.)

- Informal instrumental support services, especially for the children, elderly, physically or mentally disabled, and other vulnerable populations (e.g., extended family members caring for the young and the old, or faith communities providing meals-on-wheels, home repair, shopping, transportation, or emergency first response)

Table 2 Community interpersonal capital

Ideal interpersonal conditions

- Trust of government

- Community identification/attachment

- Community cohesiveness

- Community cooperation and tolerance

- Density of social networks and linkages between networks

- Distribution and sharing of resources and power

- Civil and human rights

- Environmental justice

- Community diversity

- Shared narratives, places, meanings, histories and spirit

Interaction means to achieve conditions (social structures mediating human interactions)

- Community leadership - informal and formal

- Informal governance

- Political organizations and citizen political involvement

- NGO adequacy vis-à-vis community needs

- Voluntary associations and membership

- Religious organizations

- Neighborhood (place based) voluntary organizations and sharing

- Friendship/family networks

- Regional/national linkages

- Print and electronic media array, diversity, access 
Figure 2 New public school elevated above flood of record (see online version for colours)

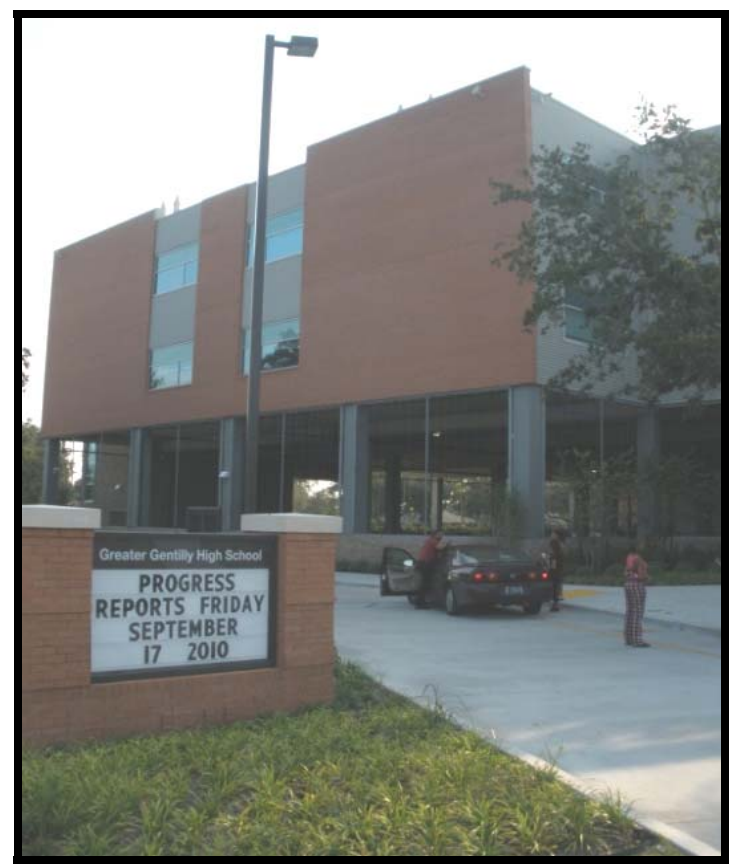

Figure 3 New public school elevated to required elevation (see online version for colours)

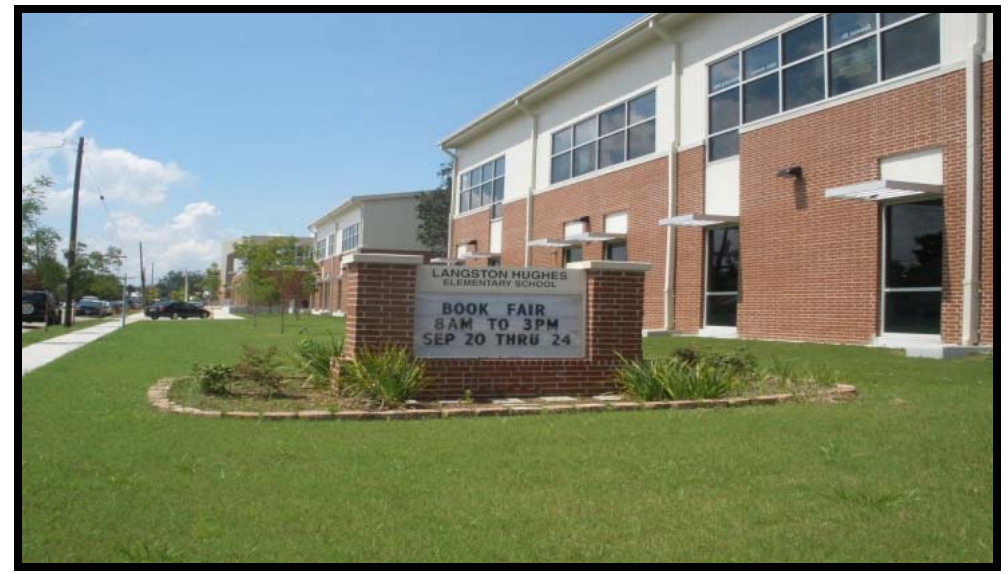

Attention to the linkage of the physical infrastructure to the social keeps the focus where it should be for essential resiliency. A current example of potentially risk-reduction-enhanced infra structure from post Katrina in New Orleans is the improved public school system. A charter school system now educates most children attending public school in New Orleans and appears to be contributing to the revitalisation of the educational process. Many of the schools were destroyed or badly damaged by the hurricane; thus these charter schools are about to occupy new buildings funded by the US 
Department of Housing and Urban Development Community Development Block Grants (CDBG). However, there are some questions about whether enhanced diligence is being paid to making sure these new structures are 'exceptionally enhanced' in storm resiliency. While they are being built to the legally required elevation (base flood elevation, BFE), there does not seem to be any additional effort underway to systematically storm proof them through additional elevation and wet and dry floodproofing. ${ }^{6}$ Some schools are elevated 'exceptionally' (Figure 2); others are only at the BFE (Figure 3).

The green building movement, i.e., construction that reduces energy usage, has been very strong in New Orleans since the hurricane. They have succeeded in getting the designers of the schools to pay attention to LEED certification ${ }^{7}$ to a certain extent but similar attention does not appear to be occurring uniformly across schools for storm resilience. ${ }^{8}$ There are no advocates and no federal encouragement/requirements to protect the key public buildings beyond the minimum requirements. ${ }^{9}$ When approached on the topic recently on the occasion of his visit to New Orleans for the fifth anniversary of Hurricane Katrina, Administrator Fugate described efforts to strengthen public buildings in Florida when he headed efforts there that he called 'mitigation plus'. ${ }^{10}$ Current legislation proposed in Congress to modify the Stafford Act would permit the use of federal mitigation funds to elevate structures to the 'flood of record' rather than to only the BFE, an option begging to be created for the sake of exceptional resilience (Laska et al., 2010).

\section{4 'Scaling up the exceptional recovery'}

The American FEMA developed a residential building flood insurance program in 1968, the National Flood Insurance Program, to stem the rising cost of tax-payer funded relief for flood victims (Federal Emergency Management Agency, 2002). It has had the secondary outcome of being an 'enabler' of communities who want to expand their footprint into flood-vulnerable areas (Burby et al., 1985). FEMA has tried to keep the insurance program solvent by developing a robust mitigation program for the homes that carry flood insurance. In 1988, the Stafford Act complemented this program with mitigation funding post disasters, the hazard mitigation grant program (HMGP). While this funding can be used for the reduction of flood risk of both public buildings as well as residential homes, the outcome by far emphasises residences (Laska et al., 2010).

In the case of modest disasters the logic of these programs makes sense. 'Capture' those homes for mitigation in specific parts of a community when they are flooded. UNO-CHART has been funded by FEMA for eight years to support just such a goal with repeatedly flooded homes. ${ }^{11}$ However, when an entire community is severely damaged (Figure 4), i.e., experiences a catastrophe, the lack of a more comprehensive mitigation effort negatively impacts the community's resilient recovery, i.e., exceptional recovery, because of a lack of focus on a neighbourhood/community scale. While $80 \%$ of the homes in New Orleans were flooded, and $100 \%$ of those in neighbouring St. Bernard Parish - a county of 30,000 homes, so too were a huge number of schools, churches, shopping areas, public housing complexes, rental apartments, Section 8 units (federally subsidised) for lower income residents, police and fire response facilities, libraries, day care centres, and a huge array of businesses. 
Figure 4 Extent of Katrina flooding (see online version for colours)

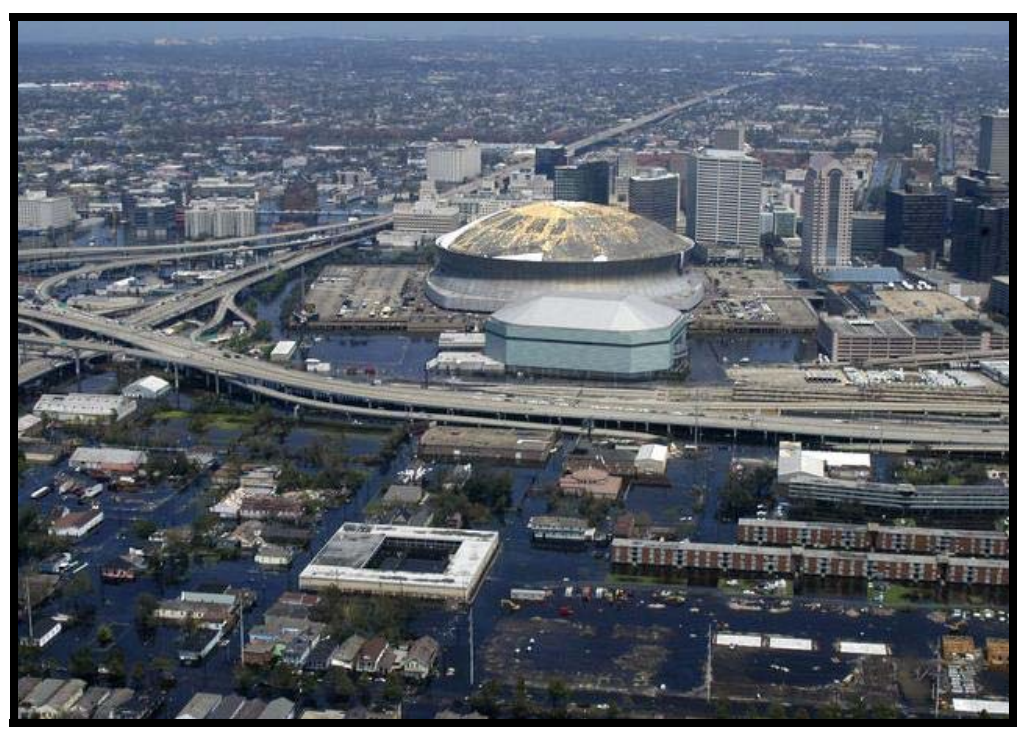

The modus operandi of mitigating one residential structure at a time with little emphasis on storm-hardening of all the types of structures that I have just listed does not use the precious mitigation funds to the best interest of the destroyed community nor the taxpayer (Figure 5). The scale of risk reduction must be at the neighbourhood and the community level (Laska, 2007). It must also encourage more drainage projects when those will mitigate the resiliency of wider areas of a community. Given the resiliency opportunity which a catastrophe provides, the 'window of opportunity' is too vast to miss. Those interested in rebuilding New Orleans in an energy efficient manner ('green') have embraced the opportunity (Laitner et al., 2007) and far surpassed the impact that we hazard mitigation advocates have been able to achieve. And, how else to achieve the physical support of the social structure and social capital that is resiliency than to focus on a broader scale of mitigation? No other logic makes sense.

Figure 5 Unsafe and safer houses elevated post Katrina (see online version for colours)

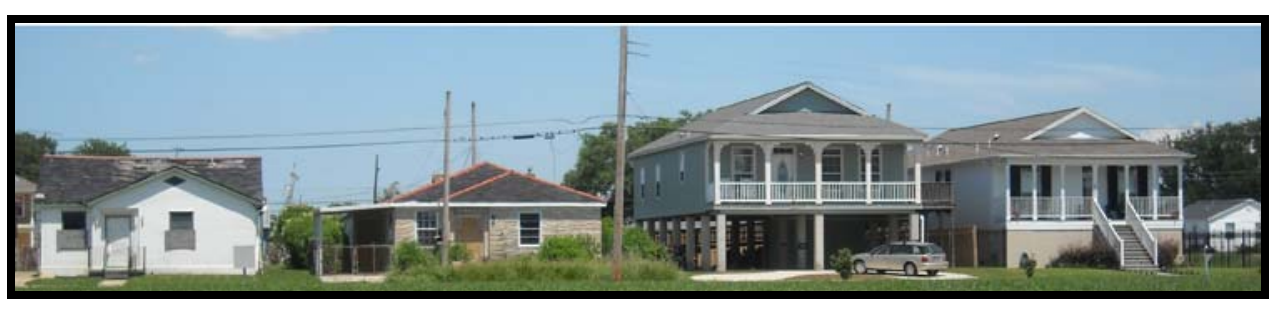

In order to overcome the harm to essential resiliency of these long-time policies, it is important to begin emphasising the 'Big Picture' of supporting resiliency within communities struck by major disasters. Physical infrastructure should be considered at the neighbourhood, district and community scale when a large amount of a community's building stock is destroyed. While the FEMA community rating system (CRS) assumes 
the philosophy that is being advocated here - addressing flooding comprehensively, it is a slow process when no disaster occurs - so many points for an array of risk reduction activities to maintain or achieve flood insurance savings for the entire community. When a major disaster occurs, the local public employees responsible for the CRS 'pieces' are engaged in more immediate response and early recovery needs such as developing a damage assessment process and then a building permit and a construction inspection process to follow. They cannot resume their usual responsibilities and thus it is difficult to reduce risk reduction through the CRS during the recovery from a severe disaster.

The harm of not emphasising 'widespread uniform flood protection' is clearly revealed when one asks the following questions about the functional challenge of spotty protection. Where would you want to locate your business if you saw a neighbourhood or district in which the public, private and residential decisions were made in a 'chorus' of risk reduction (Figure 6) versus one that is uneven with regard to flood protection (Figure 5)? Where will there be customers after another disaster? Where will there be congregants for religious organisations? Where will there be library or playground users? Where will the homes have any value at all the next time the area is flooded? ${ }^{12}$ One elevated home does not provide the owner with any future monetary benefit if the area floods again and only a few houses and other structures are elevated. If you will return to reviewing the figures one more time at the end of this paper the point is clearly made by looking together at the elevated school (Figure 2) and the non-mitigated strip mall (Figure 7). The two structures are back to back of one another only one small block apart. What essential resiliency does that logic provide for a government policy for catastrophic flood recovery? It is extremely important that we learn from recovery shortcomings of Katrina as well as the positive outcomes.

Figure 6 Neighbourhood scale of resiliency (see online version for colours)

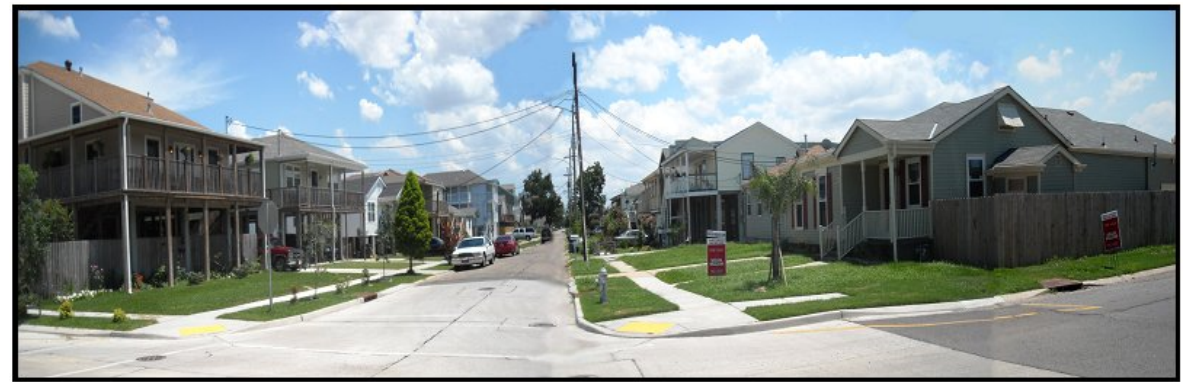

Figure 7 Strip mall (2011) with no mitigation anticipated (see online version for colours)

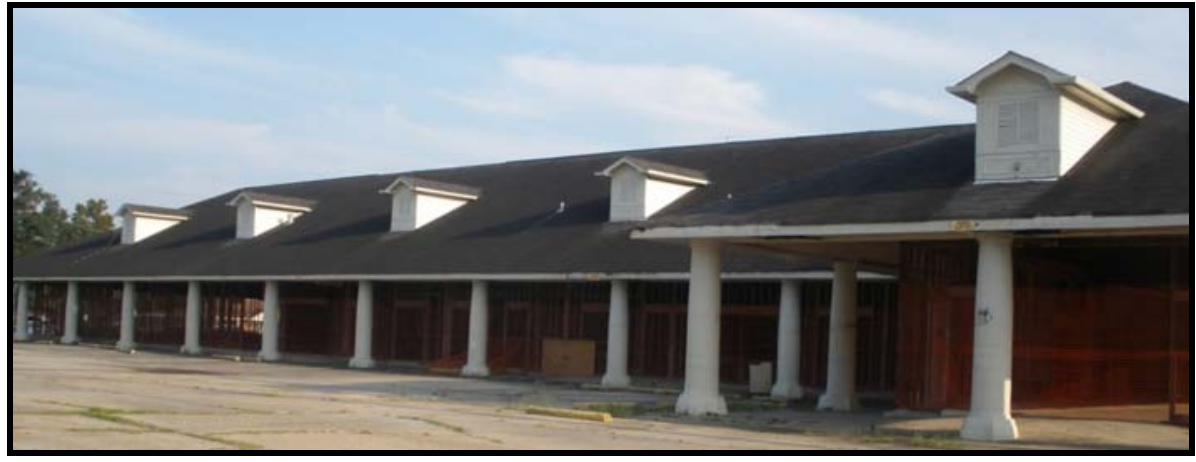




\section{Conclusions}

Advocating government support and encouragement for such a complex interplay of public, business, non-profit, religious, public and rental housing and home owner decisions to reduce risk and thus contribute to the community's essential resilience is complex and thus will require re-organisation difficult to achieve. However, there does not appear to be anything inherently prohibitive about the model in principle or in practise. However, it will require FEMA recognising the specific resiliency opportunities of extreme flood disasters and modifying mitigation policy to not only offer flood insurance for all types of buildings - residential, commercial and public, but to develop new policy to encourage - in effect require - intense risk reduction for all structures, i.e., to protect social institutions and social capitol, at a higher scale of community. It is imperative that FEMA work more pro-actively with impacted communities to use the federal-level resources for mitigation at such a broader community level.

We must:

- $\quad$ aim for the essential resiliency bedrock to achieve a mere glancing blow

- not exchange response/recovery resiliency efforts for essential resiliency - make them complementary

- require exceptional recovery

- not let ourselves get caught up in singular elements of the resiliency equation - greater scale, the more complex picture is imperative, and in addition

- continually assess how we can work for risk reduction improvements not yet even imagined.

Finally, on the ground observations of the federal government engagement with the BP oil spill response alerted this social scientist to re-think the degree to which federal level agencies are able to respond effectively to catastrophes. ${ }^{13}$ The 2011 Japanese earthquake, tsunami and nuclear power plant meltdown brought this question again to the forefront. Supporting the improved capacity of local cultures and their formal governments to appreciate these framings (essential resiliency, exceptional recovery, scale) may be the better investment. Recent research post these catastrophes in rural coastal Louisiana suggest that is the case (Laska and Peterson, 2011). Implementation of pre-disaster planning for post-disaster recovery such as has been done in the west coast of Florida (Lee County) is a new concept that is in this vein of local commitment to resiliency (Schwab, 2010).

For a place like coastal Louisiana, these important goals - community capacity and upper level government engagement - must all occur within the context of long-term recovery from the current multiple extreme disasters. It is daunting but absolutely necessary for there to be any future for such a region as at risk to extreme flood and storm damage and industrial accidents as is the human-inhabited tip of the Mississippi River Delta. 


\section{References}

Burby, R.J., French, S.P. and Cigler, B.A. (1985) Floodplain Land Use Management, Westview Press, Boulder, CO.

Cooper, M. and Walker, J. (2011) 'Genealogies of resilience: from systems ecology to the political economy of crisis adaptation', Security Dialogue, April, Vol. 41, No. 2, pp.1-18, Special Issue on Global Governance of Security and Finance.

Council of Environmental Quality (2010) Updated Principles and Guidelines for Water and Land Related Resources Implementation Studies, available at http://www.whitehouse.gov/ administration/eop/ceq/initiatives/PandG (accessed on 13 October 2010).

Donley, J. (2007) 'Buses to evacuate any who can't drive away', 26 May, NOLA.com, available at http://blog.nola.com/stormwatch/2007/05/buses_to_evacuate_any_who_cant.html (accessed on 11 October 2010).

Dunning, C.M. and Durden, S. (2007) Theoretical Underpinnings of the Other Social Effects Account, U.S. Army Corps of Engineers Institute for Water Resources, Washington, D.C., available at http://www.usace.army.mil/CECW/PlanningCOP/Documents/theo_under aug07.pdf.

Federal Emergency Management Agency (2002) National Flood Insurance Program: Program Description, available at http://www.fema.gov/library/viewRecord.do?id=1480 (accessed on 16 October 2010).

Freudenburg, W.R. (1992) 'Addictive economies: extractive industries and vulnerable localities in a changing world economy', Rural Sociology, Fall, Vol. 57, No. 3, pp.305-332.

Freudenburg, W.R., Gramling, R., Laska, S. and Erikson, K. (2008) 'Organizing hazards, engineering disasters: improving the recognition of political-economic factors in the creation of disasters', Social Forces, December, Vol. 87, No. 2, pp.1015-1038.

Jenkins, P., Kiefer, J. and Laska, S. (2010) 'Attending to the forgotten: the elderly, collaborative practice, and evacuation', in Norris-Tirell, D. (Ed.): The Practice of Strategic Collaboration: from Silos to Action, Taylor \& Francis, Washington, DC.

Jenkins, P., Laska, S. and Williamson, G. (2007) 'Connecting future evacuation to current recovery: saving the lives of older people in the next catastrophe', Generations, Vol. 31, No. 4, pp.49-52.

Laitner, M., Stella, A. and Zamoyski, M. (2007) 'Green building survey', Legislation and Public Policy, Fall, Vol. 11, No. 1, pp.81-103.

Laska, S. (2004) 'What if hurricane Ivan had not missed New Orleans?', Natural Hazards Observer, Vol. 29, 5-6 November, Invited article. Published both in paper and http://www.colorado.edu/hazards/o/nov04/nov04c.html and reprinted in Sociological Inquiry '21st century disasters: why should we care about worst cases' with companion essay by Kathleen Tierney.

Laska, S. (2007) 'Considering scale in enhancing community resilience in floodplain management', Association of State Floodplain Managers Annual Conference, June.

Laska, S. (2008) 'Mother of 'Rorschachs': New Orleans recovery from hurricane Katrina', Sociological Inquiry, Vol. 78, No. 4, pp.580-591.

Laska, S. and Morrow, B. (2006) 'Social vulnerabilities and hurricane Katrina: an unnatural disaster in New Orleans', Journal of the Marine Technology Society, Vol. 40, No. 3, pp.7-17.

Laska, S. and Peterson, K. (2011) 'The convergence of catastrophes and social change the role of participatory action research in support of the new engaged citizen', Journal of Applied Social Science, Spring, Vol. 5, No. 1, pp.24-36.

Laska, S., Gramling, R., Berginnis, C.M., Farris, M., Freudenburg, W., Gremillion, M., Jenkins, P., Krajeski, R., McCombs, H., Mock, N., Morrow, B., Ott, B., Peterson, K. and Taylor, H. (2009) Expanding the Identification and Measurement of the Human Consequences of Disastrous Flooding: Toward the Refinement of the 'Other Social Effects' Account, Vol. I, Economics Appendix, Attachment 2, p.159, 105 pp., of U.S. Army Corps of Engineers, Louisiana Coastal Protection and Restoration Report (LACPR) to the U.S. Congress, available at http://lacpr.usace.army.mil/FinalReport/Vol\%20I/Economics.pdf (accessed on 17 October 2010). 
Laska, S., Jenkins, P., Montjoy, R., Birkland, T., Nowell, B., Farris, M.T., Gremillion, M., Devalcourt, J. and King, K.C. (2010) Achieving Successful Long-Term Recovery and Safety from a Catastrophe: The Federal Role, June, Ford, New York, NY.

Lopez, J. (2008) Comprehensive Recommendations Supporting the Use of the Multiple Lines of Defense Strategy to Sustain Coastal Louisiana, Version I, available at http://www.saveourlake.org/multiple-lines-of-defense.php (accessed on 10 October 2010).

Schwab, J.C. (Ed.) (2010) Hazard Mitigation: Integrating Best Practices into Planning, pp.60-73, American Planning Association, Planning Advisory Service Report No. 560, American Planning Association.

Tatsuki, S. and Comafay, N. (2010) Evacuation and Sheltering Assistance Planning for Special Needs Populations: Kobe Disadvantaged Population Mapping Project, 15th July, International Sociological Assoc., Gottenburg, Sweden.

The White House (2006) The Federal Response to Hurricane Katrina: Lessons Learned, The White House, Washington, DC.

White, G. (1960) 'Strategic aspects of urban flood plain occupancy', Journal of Hydraulics Division, Proceedings of American Society of Civil Engineers, Vol. 86, No. HY2, pp.89-102.

Youngman, N. (2011) 'Swamped: growth machines and the manufacture of flood risk in mid-20th Century New Orleans', Doctoral dissertation, Tulane University.

\section{Notes}

1 In addition very recent work even suggests that bio-ecosystem resiliency might demonstrate statuses quite antithetical to the goals of human communities, i.e., that 'crashes' are functional and disequilibrium normal (Cooper and Walker, 2011).

2 Applied research done before hurricane Katrina by UNO-CHART in support of efforts to partner evacuating faith congregants with car-less congregants led to an estimate from the 2,000 U.S. Census of 125,000 New Orleanians without cars (Laska, 2004; Jenkins et al., 2007, 2010). This estimate was captured by media and scholars and used frequently post-Katrina to describe the challenge of the lower-income residents of the city in evacuating for Katrina. The 109,000 beds currently available for evacuees is in line with that number because it includes those with cars who don't have money for shelter and is a regional need, not just one for the central city county - Orleans - that now has 100,000 fewer people than before Katrina.

3 Personal communication, Casey Levy, Governor's Office of Homeland Security, Oct., 2010.

4 Congressional response to Katrina required that the Corps be committed to judging projects with the OSE's in mind as well as the other three: "While the 1983 standards emphasized economic development alone, the new approach calls for development of water resources projects based on sound science that maximize net national economic, environmental, and social benefits". (Council of Environmental Quality, 2010) As the process of creating the Principles and Guidelines have gone forward, some within the Corps are concerned that this social benefits requirement is being 'watered down' due to the reluctance to develop means of assessing such benefits. Therefore, again, inadequate consideration of the social benefits will result (Personal communications.)

5 Some American disaster specialists disagree with Dutch and American civil engineers who cast their lot with large infrastructure projects that are seen as being an easier approach to protect the physical infrastructure needed to accomplish the protection of social structure and social capitol. One person is John Lopez, creator of the 'Multiple Lines of Defense' (2008). Attempting to reduce flood risk through large-scale physical structures is seen by critics to be a low annoyance effort for modest flooding risk reduction but a high risk solution for large events unless massive structures are put into place with both huge monetary and environmental costs (White, 1960). As Gilbert White is quoted frequently: "There are only two types of levees: those that have failed and those that will".

6 Wet floodproofing focuses on building materials that are resistant to water; dry on keeping water out of the structure by means of barriers. 
7 According to the U.S. Green Building Council the Leadership in Energy and Environmental Design (LEED) green building certification program "encourages and accelerates global adoption of sustainable green building and development practices through a suite of rating systems that recognize projects that implement strategies for better environmental and health performance".

8 Personal conversation with community LEED activists.

9 The hazard-strengthening of critical infrastructure is required by the federal government through a dated Executive Order, but strict enforcement does not occur. Mitigation specialists are pushing for a new executive order for critical infrastructure hoping that it would spark renewed attention to the issue. However, it will likely not include the broad spectrum of public buildings to which this paper is referring. Personal communication with Larry Buss, U.S. Army Corps of Engineers, retired.

10 Personal communication with Craig Fugate, August 28, 2010.

11 See www.floodhelp.uno.edu for a description of this program.

12 Content from workshop presentations currently being made by UNO-CHART team as subcontractors to the state of Louisiana's Governor's Office of Homeland Security and Emergency Preparedness (GOHSEP) Community Education and Outreach (CEO) program funded by FEMA through HMGP Katrina funds.

13 Cooper and Walker (2011) report from the U.S. Department of Homeland Security's post-Katrina report to the effect that the "manifest failure of federal preparedness and evacuation procedures in New Orleans (suggests sic) that it is 'unrealistic' to expect the government to respond effectively to the challenges of catastrophic risk in the 21 st century" [The White House, (2006), p.52]. 